\title{
How wrong were we? Dependent interviewing, self- reports and measurement error in occupational mobility in panel surveys
}

Francisco Perales, Institute for Social Science Research, The University of Queensland f.perales@uq.edu.au

(Received February 2014 Revised September 2014) http://dx.doi.org/10.14301/llcs.v5i3.295

\section{Abstract}

Occupation is a central concept in sociology and economics, and individual change in occupation is of major importance to literatures on wage determination, human capital, careers and social mobility. The collection of occupational data in surveys, particularly panel surveys, is challenging due to measurement error, and observed rates of occupational mobility are argued to be overestimated. We use a methodological discontinuity in the collection of occupational data from independent interviewing (respondents are asked to describe their occupation each year) to dependent interviewing (respondents are shown their previous response and only asked to describe their occupation if this has changed) and information on self-reported occupational changes in two panel surveys to estimate the degree of error in occupational mobility in panel data. We also test whether observed patterns differ by the level of aggregation of occupational classifications and examine the external validity of different measures of occupational mobility through their predicted impacts on selected labour market outcomes. Results indicate that occupational mobility is dramatically lower under dependent than independent interviewing (particularly for highly disaggregated occupational classifications) and that there is an evident mismatch between respondents' self-reports of occupational switches and mobility measures inferred from changes in occupational codes. The impacts of occupational changes on earnings and job satisfaction are more consistent with theoretical predictions under dependent than independent interviewing and when occupational mobility is inferred from respondents' self-reports. These findings have important implications for survey design, question the validity of existing studies on occupational change and call for further research.

Keywords: Occupation, occupational mobility, measurement error, dependent interviewing, self-reports, wages, job satisfaction, panel data

\section{Introduction}

The study of occupation has a long tradition in Sociology and Economics, and occupation serves as a core concept in research on wage determination, human capital acquisition, careers, social stratification and social mobility, and other fields such as social and friendship networks or cultural consumption (Blau \& Duncan, 1967; Chan \& Goldthorpe, 2007; De Beyer \& Knight, 1989; Kambourov \& Manovskii, 2008; Perales, 2013;
Polachek, 1981; Sorensen, 1974). Occupations, understood as identifiable lines of economic activity requiring specific skills, knowledge and duties (Lee, Carswell \& Allen, 2000), are however not easy to delineate or capture empirically. This is evidenced by the large number of existing occupational classifications, the diversity of structural principles used in creating these and the evident heterogeneity in the number of hierarchical levels and occupational titles they encompass. Besides, in post-modern societies, occupations are fluid 
entities which emerge, evolve, disappear and reappear with changes in the structure of work (Abbott, 1989; Sobek, 1996). As a consequence, classifications often become obsolete and are superseded by new versions or completely new instruments.

In social research there is a fundamental problem in how occupational data are to be collected in surveys. Typically, survey participants are prompted to describe the line of work that they do, and their verbatim answers are later coded by a person (the coder) or a computer program as a given occupational unit of a previously determined occupational classification. This process is, however, subject to measurement error from a number of sources.' These include incomplete descriptions reported by respondents, inaccurate records made by interviewers and, more acutely, incorrect allocation of such reports into occupational units by coders (Laurie \& Moon, 2003; Lynn \& Sala, 2006; Mellow \& Sider, 1983; Moscarini \& Thomsson, 2007; Watson \& Summerfield, 2009). For the latter, a common method of quality control is to calculate the degree to which different coders agree on the proper classification of respondents' descriptions of their occupation, also known as the inter-coder reliability (Groves, 1989). Research suggests that agreement rates for occupational data between two separate coders are far from optimal, and as low as $50 \%$ in some social surveys (Elias, 1997; Campanelli, Thomson, Moon \& Staples, 1997; Laurie \& Moon, 2003). ${ }^{\mathrm{it}}$

A large share of the academic interest in occupations has an inherent longitudinal dimension.ii We are interested in what prompts people to switch the type of work they do (Evans, 1999; Harper, 1995), in how individuals move across successions of occupations over their life courses and develop a 'career' (Budoki \& Dex, 2010; Jacobs, 1999) and on the impact occupational changes have on labour market outcomes such as earnings and job satisfaction (Kambourov \& Manovskii, 2008; Longhi \& Brynin, 2010; Wilson \& Green, 1990). Obtaining robust answers to these questions requires the use of longitudinal data, with panel datasets being considered the 'gold standard'. Unfortunately, the complexities inherent in the measurement of occupation outlined before are exacerbated in the context of panel data. Typically, the method used to collect information on occupation in panel surveys is the same as that used in cross-sectional surveys: each year respondents are asked about the line of work they are engaged in, with their answers coded into a certain occupational unit. Since the process of occupational coding is error prone each year, this implies not only that there is a high probability of coding an individual into the wrong occupational unit in any given survey wave, but also that the probability of coding an individual into a wrong occupational unit in at least one of two subsequent years is even higher (Hill, 1994; Sullivan, 2009). For example, a person working continuously as a "Court and Legal Clerk" (detailed code 5992 of the current Australian occupational classification) might have been coded as such in one year and as a "Secretary" (code 5212) in the next, due to standard coding error. Furthermore, even at an acceptable rate of coding reliability of $80 \%$, coder variance means that in a panel dataset, one would expect to observe spurious mobility episodes for a shocking $20 \%$ of cases in a sample of occupational 'stayers' who give the exact same occupational description in two consecutive survey waves (Campanelli et al., 1997; Lynn and Sala, 2006). As a result, when researchers use changes in occupational codes across panel survey waves as evidence of individuals changing occupations, the likelihood of identifying spurious change can be alarmingly high. Despite this being potentially catastrophic for longitudinal research using occupational data, there is surprisingly little literature and even less empirical evidence on the issue - with the exceptions of Isaoglu (2010), Lynn \& Sala (2006) and Moscarini \& Thomsson (2007). A reason for this is that there are usually no means to tell whether the observed occupational switches are spurious and a product of survey error, or genuine changes in the nature of the work that individuals perform over time. This has elicited a debate over whether the conspicuously large rates of occupational mobility reported in past research are indeed genuine (Isaoglu, 2010; Longhi \& Brynin, 2010). Additionally, findings stemming from research studies which take a non-critical approach to the quality of occupational mobility data in panel studies might be biased.

In this paper, we add to the limited body of existing knowledge and attempt to shed light over these issues by undertaking separate analyses of two different panel surveys: the British Household Panel Survey (BHPS) and the Household, Income and Labour Dynamics in Australia (HILDA) Survey. 
First, we estimate the degree of error in yearly rates of occupational mobility inferred from changes in occupational codes across adjacent survey waves using data from the BHPS. To do so, we exploit a change in the methodology used to collect information on occupation in this study from independent interviewing (respondents are asked to describe their occupation each year) to dependent interviewing (respondents are shown their previous response and only asked to describe their occupation if this has changed). Second, we capitalize on the availability of a self-reported measure of occupational mobility in the HILDA Survey to compare the prevalence of year-on-year occupational mobility as denoted by changes in occupational codes across adjacent survey waves and respondents' self-reports. Additionally, we test whether any observed patterns differ by the level of aggregation of occupational data and examine the external validity of different measures of occupational mobility through their predicted impacts on selected labour market outcomes.

Key findings indicate that occupational mobility rates inferred from occupational codes are implausibly high when occupation-related panel data are collected via independent interviewing, do not match respondents' self-reports and fall substantially with dependent interviewing. The performance of occupational mobility measures improves when dependent interviewing is used, and self-reported occupational mobility measures perform better than measures based on changes in occupational codes under independent interviewing. These results have important implications for the collection of longitudinal data on individuals' occupation of work, and cast doubts on the validity of existing evidence on occupational mobility from studies that take for granted the quality of occupational change data in panel surveys.

The remaining sections in this paper will sequentially address themes in occupational mobility research; useful features of occupation data in the BHPS (i.e. introduction of dependent interviewing) and the HILDA Survey (i.e. availability of a selfreported measure of occupational change); the nature and structure of occupational classifications in these datasets; new empirical evidence on measurement error in occupational mobility in panel studies; and a discussion of the associated findings.

\section{Background}

\section{Occupational mobility in the academic literature}

The concept of 'occupation' is broader than that of 'job'. Occupation denotes a line or type of work, without reference to a specific workplace, firm or employer. Hence, occupation and job changes cannot be equated. Employees can change jobs without changing occupations - for instance, a primary school teacher who moves from school A to school B - but the opposite is improbable. In sociology, research on occupational mobility is, to a large extent, embedded in the literatures on status attainment and occupational (or class) careers. Occupations drive the structure of economic and social welfare and movement across occupations is seen as a vehicle for upward social mobility (Blau \& Duncan, 1967; Goldthorpe, 1987). Additionally, occupational change might be a channel for career adjustment as a response to poor early career decisions or evolving preferences (Longhi \& Brynin, 2010). In economics, mobility has more often been studied at the level of jobs than of occupations. The discussion revolves around the notion of 'utility' using a rational choice theoretical framework (Borjas, 1981). In very simplified terms, changing job and/or occupation is a risky and potentially costly process. Workers only incur such changes if there is an inherent motivation, that is, if the expected utility from doing so exceeds the utility of staying in the current position, minus the costs associated with the change (Booth \& Francesconi, 1999). Such costs include direct economic costs, opportunity costs and psychological costs (Groot \& Veberne, 1997). In empirical research designs, evidence of labour market mobility being associated with increases in social standing and utility gains is gathered using proxies such as wage gains and growth in job satisfaction (see e.g. Longhi \& Brynin, 2010; Parrado, Caner \& Wolff, 2007; Wilson \& Green, 1990). .

Empirically, there are different ways through which occupational mobility can be identified in survey data. Most commonly, longitudinal data are used and a comparison of the codes attributed to respondents in different survey waves undertaken to distinguish mobility from stability. While early sociological interest in status attainment emphasized divergences between occupation at labour market entry and current or last occupation (Featherman, Lancaster Jones \& Hauser, 1975), interest has progressively shifted to the analysis of 
more complex successions of several adjacent occupational spells (Budoki \& Dex, 2010; Jacobs, 1999). American and British evidence suggests that occupational mobility is pervasive. Parrado et al. (2007) and Kambourov and Manovskii (2008) report that in the US, between $10 \%$ and $20 \%$ of workers change occupations each year, with rates varying with the degree of aggregation used to measure occupation. Moscarini and Thomsson (2007) report even higher rates of up to $35 \%$ per month using highly disaggregated occupational data. Raw (uncorrected) estimates of $11-45 \%$ have been reported for Germany (Isaoglu, 2010; Longhi \& Brynin, 2010) and of 20$53 \%$ for Britain (Longhi \& Brynin, 2010; Lynn \& Sala, 2006). For the reasons outlined before, the degree of error in occupational mobility reported in previous research is likely to be high, with existing research suggesting that implementation of dependent interviewing practices might reduce misclassification of occupational movers (Lynn \& Sala, 2006; Moscarini \& Thomsson, 2007) and proposing potential corrections when information on job changes is also available (Isaoglu, 2010; Longhi \& Brynin, 2010).

\section{Dependent interviewing and occupational mobility: the case of the British Household Panel Survey}

The British Household Panel Survey (BHPS) is an annual household panel survey which began in 1991 and is representative of individuals living in Britain that year (Taylor, Brice, Buck \& PrenticeLane, 2010). This is one of the largest and bestestablished household panel surveys in the world and is part of the Cross National Equivalence File (CNEF). Up to wave 15 of the survey (2005) occupational data were collected by independent interviewing. Regardless of their responses in previous years, survey respondents were asked to answer the following question: "What was your (main) job last week? Please tell me the exact job title and describe fully the sort of work you do". In its $16^{\text {th }}$ wave $(2006)$ the study experienced a change in the way in which data on employment characteristics and household finances, including data on occupation, were collected. The new methodology consisted of (proactive) dependent interviewing. In broad terms, the routing process involved respondents being shown their report of their occupation in their last interview and asked whether the same description applied to their current occupation. If respondents answered 'yes', the interview continued as normal. If respondents answered ' $n o$ ', they were then prompted to answer the independent interviewing question reproduced above. More detailed information on the motivation, aims and considerations on the introduction of dependent interviewing on the BHPS as well as on the actual procedure can be found in Jäckle, Laurie and Uhrig (2007).

This seemingly small change in the way in which occupation-related information is collected should minimize the risk that respondents' answers are coded into the wrong occupational group and reduce the emergence of spurious occupational changes. This methodological discontinuity is used to explore to what degree previous estimates of occupational change in that study were artificial, and the product of coding error.

\section{Self-reported occupational mobility: the case of the Household, Income and Labour Dynamics in Australia Survey}

The Household, Income and Labour Dynamics in Australia (HILDA) Survey is also a major annual panel dataset (Watson \& Wooden, 2012). This survey was designed using the BHPS as a model, thus resembling it in its structure, and is also part of the CNEF. The HILDA Survey tracks a representative sample of the Australian population since 2001. Unlike the BHPS, information on occupation is collected in the 'traditional' manner, i.e. via independent interviewing, throughout the entire life of the survey. The actual questionnaire item is placed after a battery of questions on the current main job and reads: "What kind of work do you do in this job? That is, what is your occupation called and what are the main tasks and duties you undertake in this job? Please describe fully".

The HILDA Survey data are complementary to the BHPS data and enable us to gain further insights into occupational mobility. Specifically, the HILDA Survey includes a question which asks respondents: "Has your occupation changed since [date of last interview]? Note that a promotion or a change in employer does not necessarily mean a change in occupation". This will allow us to estimate the degree of misclassification in occupational mobility when this is inferred from a comparison of respondents' occupational codes across survey releases. 


\section{Occupational data in the British Household Panel Survey and the Household, Income and Labour Dynamics in Australia Survey}

The BHPS analysis covers the period 1991-2008. ${ }^{v}$ The information on occupation of employment in the BHPS is coded into several classifications. In all survey years, occupational data are available using the 1990 Standard Occupational Classification (SOC90). SOC90 clusters jobs into occupations in terms of their content and the educational qualifications, training and work experience required to carry out the associated tasks and duties. It has a hierarchical structure divided into four levels, each denoting a different degree of occupational aggregation. It features 9 major occupational groups, 22 sub-major groups, 77 minor occupational groups and 371 unit groups. A revision of this classification, SOC2000, is available in the data since wave 10 (2001). SOC2000 is also arranged hierarchically, but the number of occupations at each aggregation level differs slightly from that in SOC90. SOC2000 features 9 major groups, 27 sub-major groups, 81 minor groups and 353 unit groups. The change in the survey practices used to collect occupational data in the BHPS from dependent to independent interviewing took in place in 2006. Thus, we can test the impact this had on occupational mobility inferred from wave-on-wave changes in occupational codes from both the SOC90 and SOC2000 classifications. The use of both schemes will enable us to gather more robust evidence that any effects found are genuine.

The analysis of the HILDA Survey covers the period 2001-2012. In the HILDA Survey occupational data are collected using the 2006 Australian and New Zealand Standard Classification of Occupations (ANZSCO06) in all survey waves. In ANZSCO06, occupations are organized on the basis of their similarities in terms of both skill level and skill specialization into four levels of occupational aggregation. These include 8 major groups, 43 sub-major groups, 97 minor groups and 358 unit groups. Note that information on respondents' detailed occupation (i.e. the 3- and 4digit levels) in the HILDA Survey is only available in its 'unconfidentialised' version.

Throughout the paper we compare results at all available levels of aggregation for the occupational classifications used. This is important because, as the specificity of occupational units increases, the probability of measurement error should also increase (Elias, 1997; Laurie \& Moon, 2003; Lynn \& Sala, 2006; Sullivan, 2009).

\section{Research hypotheses}

Based on the above discussion, we formulate several simple, testable hypotheses:

Hypothesis 1 (BHPS) - The introduction of dependent interviewing will reduce the observed rates of occupational mobility in the British labour market captured in the BHPS data.

Hypothesis 2 (BHPS) - The fall in observed occupational mobility after the introduction of dependent interviewing in the BHPS data will be more apparent when using highly disaggregated versions of occupational classifications.

Hypothesis 3 (HILDA) - Rates of occupational change inferred from respondents' self-reports will be lower than those inferred from changes in occupational codes across survey waves.

Hypothesis 4 (BHPS) - The impacts of occupational changes on labour market outcomes (namely, wages and job satisfaction) will be more consistent with theoretical predictions after the introduction of dependent interviewing.

Hypothesis 5 (HILDA) - The impacts of occupational mobility on wages and job satisfaction will be more consistent with theory when occupational mobility is inferred from respondents' self-reports rather than from changes in occupational codes.

\section{Results}

\section{Empirical evidence}

We now present the results of our empirical enquiries and test the above hypotheses. First, we will present trends in occupational mobility rates in Britain and Australia under different interview conditions (dependent and independent interviewing) and using different specifications of occupational change (different occupational codes vs. self-reports). Second, we will examine for which measures the predicted impacts of occupational mobility on labour market outcomes most closely resemble the expectations from sociological and economic theory.

All subsequent analyses include only employees who were interviewed and in paid employment at times $\mathrm{t}$ and $\mathrm{t}-1$, and exclude individuals who move from self-employment, unemployment or inactivity into employment (or vice versa), and those for which there is missing data in either of the adjacent survey waves. 
Trends in occupational mobility in Britain and Australia

Figure 1 shows trends in occupational mobility in Britain between 1991 and 2008 using BHPS data. Each data point gives the percentage of workers who changed occupations between a given survey wave and the previous, inferred by such individuals having a different occupational code. Each coloured line shows the results for a different level of aggregation of the SOC90 occupational classification. The discontinuous vertical line denotes the time point when the methodology employed to collect occupation-related information in the BHPS changed from independent to dependent interviewing.

Many interesting findings emerge from this simple trend graph. First, in the period between 1992 and 2005, occupational change seems conspicuously high. For instance, between 1999 and 2000 over $40 \%$ of all workers appear to have changed detailed occupational units. Second, in the same time period there is evidence of a small increase (of around 5 percentage points) in mobility rates. Third, the more disaggregated the classification used, the higher the rates of occupational mobility observed. In the 1992-2005 period, about $35-40 \%$ of workers seem to change detailed occupational units each year, but 'only' 20$25 \%$ change major occupational groups. As lines of work become more disaggregated they become more similar to each other. Thus, one would expect mobility rates within major occupational groups and across detailed occupational units to be high. However, the extremely large size of the divergences suggests that measurement error exists. Fourth and most significantly, the introduction of dependent interviewing radically reduces the occupational mobility rates observed in the BHPS data. For example, rates at the 4-digit level of occupational aggregation, which were about $40 \%$ in the 2004-2005 period, fall to about $15 \%$ in the $2007-2008$ period.

Figure 1. Occupational mobility in the BHPS, SOC90

\section{Yearly occupational mobility rates (BHPS)}

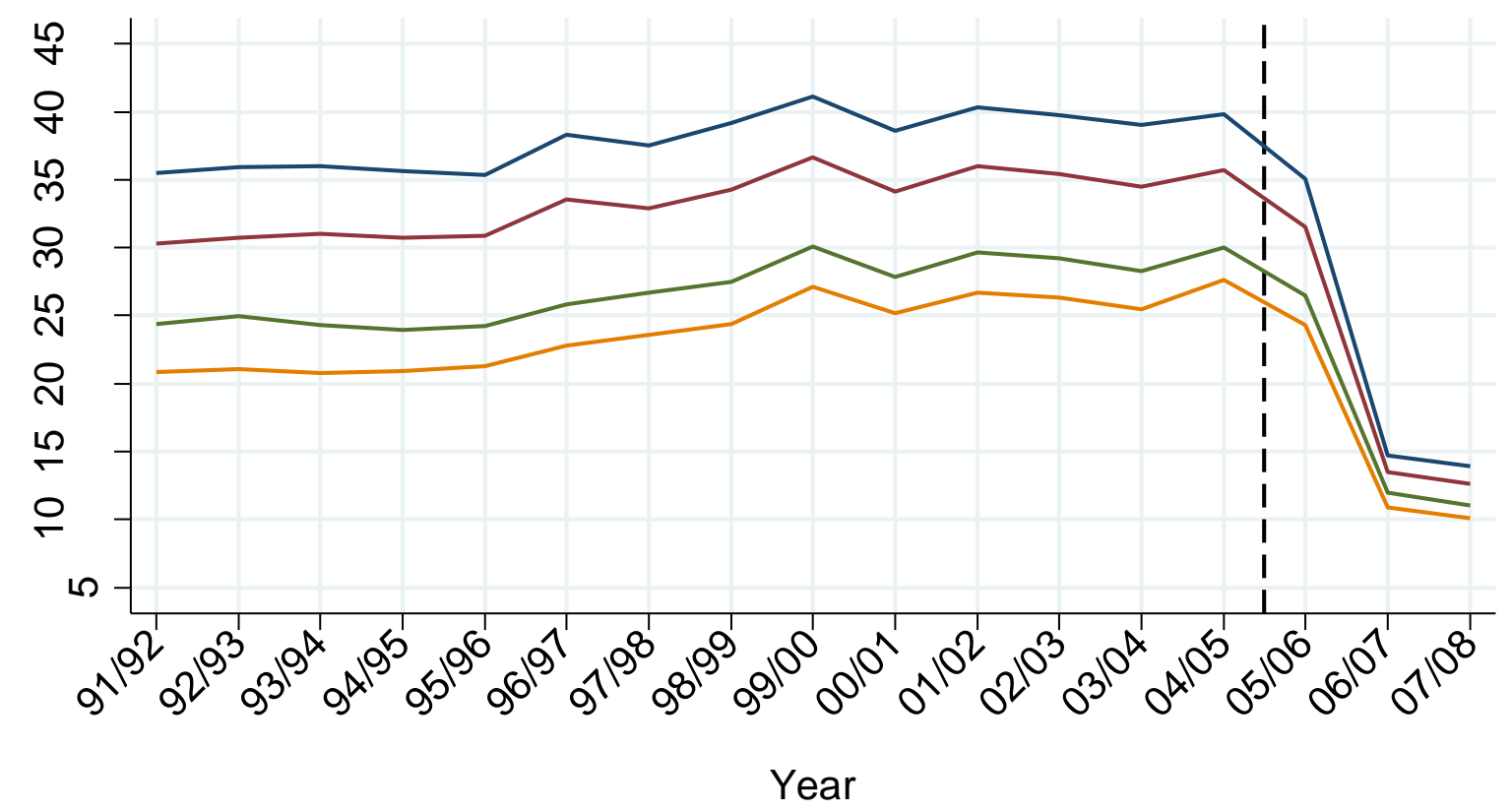

$$
\begin{array}{lr}
\text { 4-digit SOC90 } & \text { 3-digit SOC90 } \\
\text { 2-digit SOC90 } & \text { 1-digit SOC90 }
\end{array}
$$


It is possible that the break in the time series associated with the introduction of dependent interviewing reported above is confined to the occupational classification we used (SOC90). This poses the question: does the pattern also emerge for other classifications? Results in Figure 2 suggest that the trend is also apparent when using SOC2000. For those years in which the SOC2000 classification is available (2002-2008), the pattern is very similar to that in Figure 1: overall occupational mobility drops dramatically after the introduction of dependent interviewing.

Figure 2. Occupational mobility in the BHPS, SOC2000

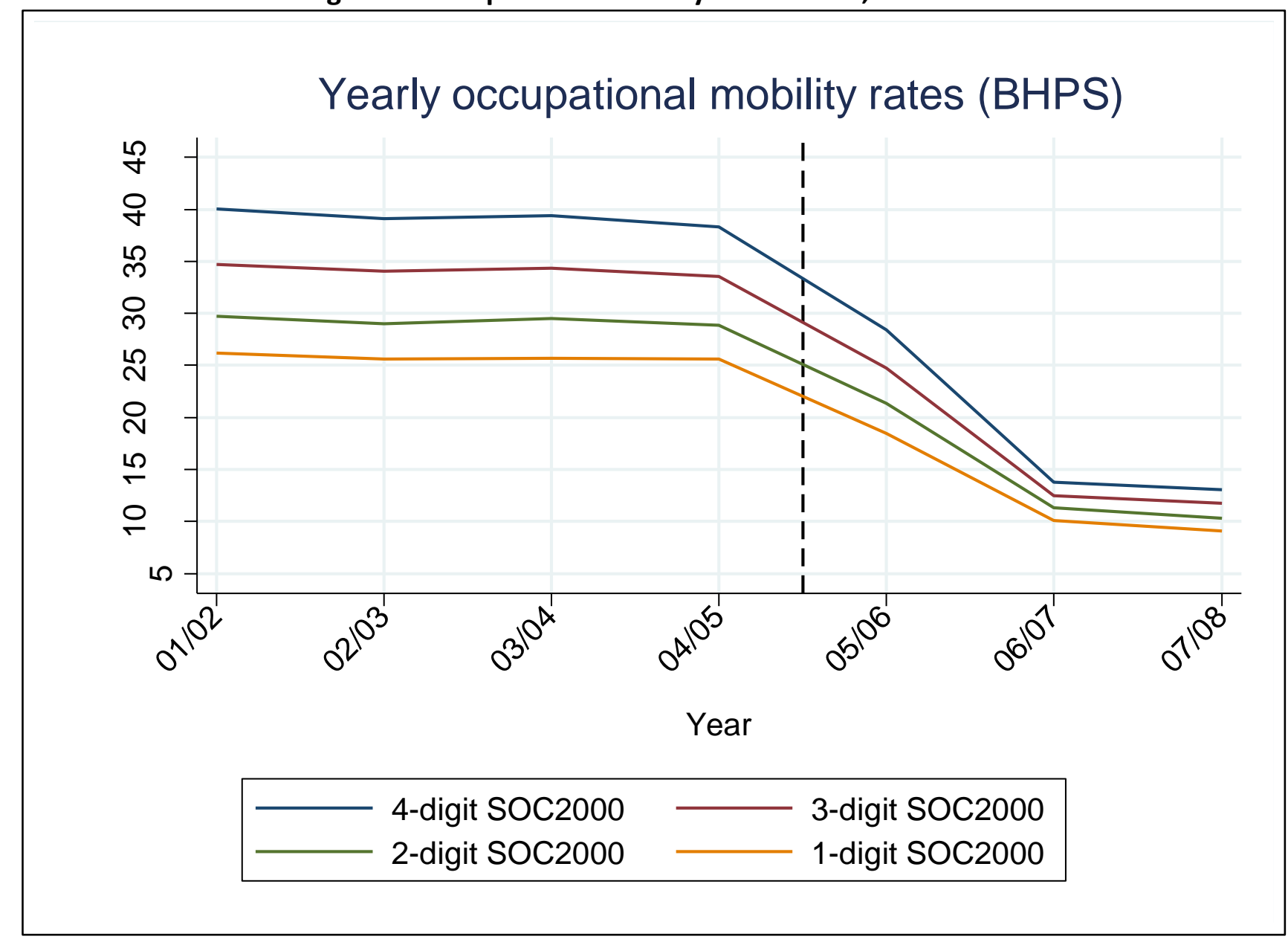

Unexpectedly, the reduction in occupational mobility occurring after the introduction of dependent interviewing in Figures 1 and 2 seems to have taken place in an odd, step-wise fashion: rates reduce only slightly in 2006, drop more substantially in 2007, and stabilize in 2008. While this pattern is counter-intuitive, there are three additive and inter-related reasons why the introduction of dependent interviewing practices in wave 16 (2006) of the BHPS did not result in an immediate fall in occupational mobility rates. First, 1,152 (or $18 \%$ ) of the in-scope respondents did not have valid occupational descriptions to be fed forward from wave 15 for dependent interviewing in wave 16 (despite having seemingly valid occupational codes in wave 15). The occupation information for these respondents in wave 16 was subsequently collected via independent interviewing (Jäckle et al. 2007), for which we have shown that longitudinal consistency is poor. This increased the observed rate of occupational mobility for wave 16 . In contrast, in waves 17 (2007) and 18 (2008) just 115 (or 2\%) and 62 (or $1 \%)$ of the in-scope respondents had no valid occupational descriptions to be fed forward, respectively. Second, for no apparent reason, a non-negligible number of wave 16 respondents were assigned different occupational codes, despite having confirmed that their occupation was the same as in wave 15 via dependent interviewing. For 
example, this affected the detailed SOC2000 codes of 1,359 wave 16 respondents. The number of entries affected by this inconsistency reduced markedly in waves 17 (175 respondents) and 18 (156 respondents). Third, substantive 'cleaning' work was undertaken to streamline wave 15 verbatim occupational descriptions to be used during dependent interviewing in wave 16, and this might have prompted some respondents to erroneously infer and report an occupational change. As documented by Jäckle et al. (2007, p. 21): "responses [...] underwent an editing process to ensure that the descriptions were readable, to correct spelling errors and where necessary to shorten the description. For example, if at the last interview a respondent had reported their job title plus a lengthy job description of the tasks they actually did in their job, this was edited to include the job title and the key feature of their job". Reportedly, this was "a non-trivial task" that "at subsequent waves should be significantly reduced, as only those responses where new information has been entered will need to be checked" (Jäckle et al. 2007, p. 22). Therefore, the unexpected trend in occupational mobility rates following the introduction of dependent interviewing in the BHPS is simply the product of errors associated with the complex transition from independent interviewing.

Suspecting that spurious occupational changes are commonplace in panel data, a handful of previous studies have attempted to partially correct for this by considering job mobility information in conjunction with changes in occupational codes to identify occupational mobility (see e.g. Isaoglu, 2010; Longhi \& Brynin, 2010). In these studies, changes in occupational codes across waves are only taken as evidence of occupational mobility if respondents incur also a job change between such waves. In the BHPS, job changes can be inferred from a separate question reading: "What was the date you started working in your present position? If you have been promoted or changed grades, please give me the date of that change. Otherwise please give me the date when you started doing the job you are doing now for your present employer". Note however that answers to this question are also likely to be 'noisy', due to respondents being unsure about the exact meaning of terms such as 'position', 'grade' or 'employer', recall biases and other survey errors (Brown \& Light, 1992).

In Figure 3 (SOC90) and Figure 4 (SOC2000) we present trends in occupational mobility in Britain using the definition of occupational change that incorporates information on job changes. Three aspects stand out. First, within the independent interviewing period, rates of occupational mobility more than halve relative to those in Figures 1 and 2 . Second, the downward trend after the implementation of dependent interviewing in the BHPS, despite being less marked, is still highly visible. Third, within the dependent interviewing period, rates of occupational mobility are comparable to those in Figures 1 and 2. This suggests that under independent interviewing conditions, using job mobility information might partially correct for spurious occupational mobility due to measurement error. While it could be argued that a sharp fall in occupational mobility could also be due to rapid and marked exogenous labour market changes, the BHPS data was collected before the great economic recession affecting Britain from 2008. 
Figure 3. Occupational mobility conditional on job change in the BHPS, SOC90

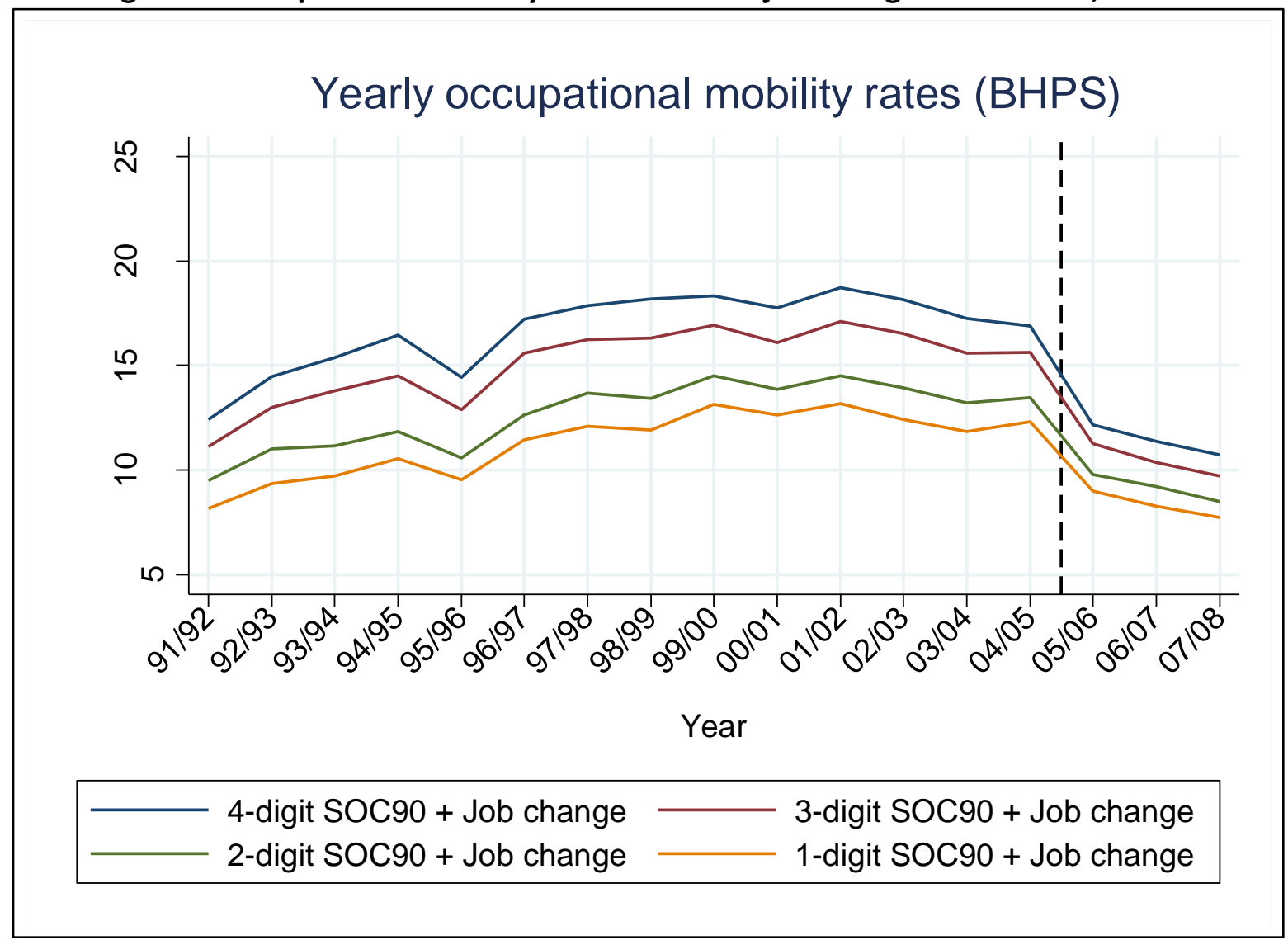

Figure 4. Occupational mobility conditional on job change in the BHPS, SOC2000

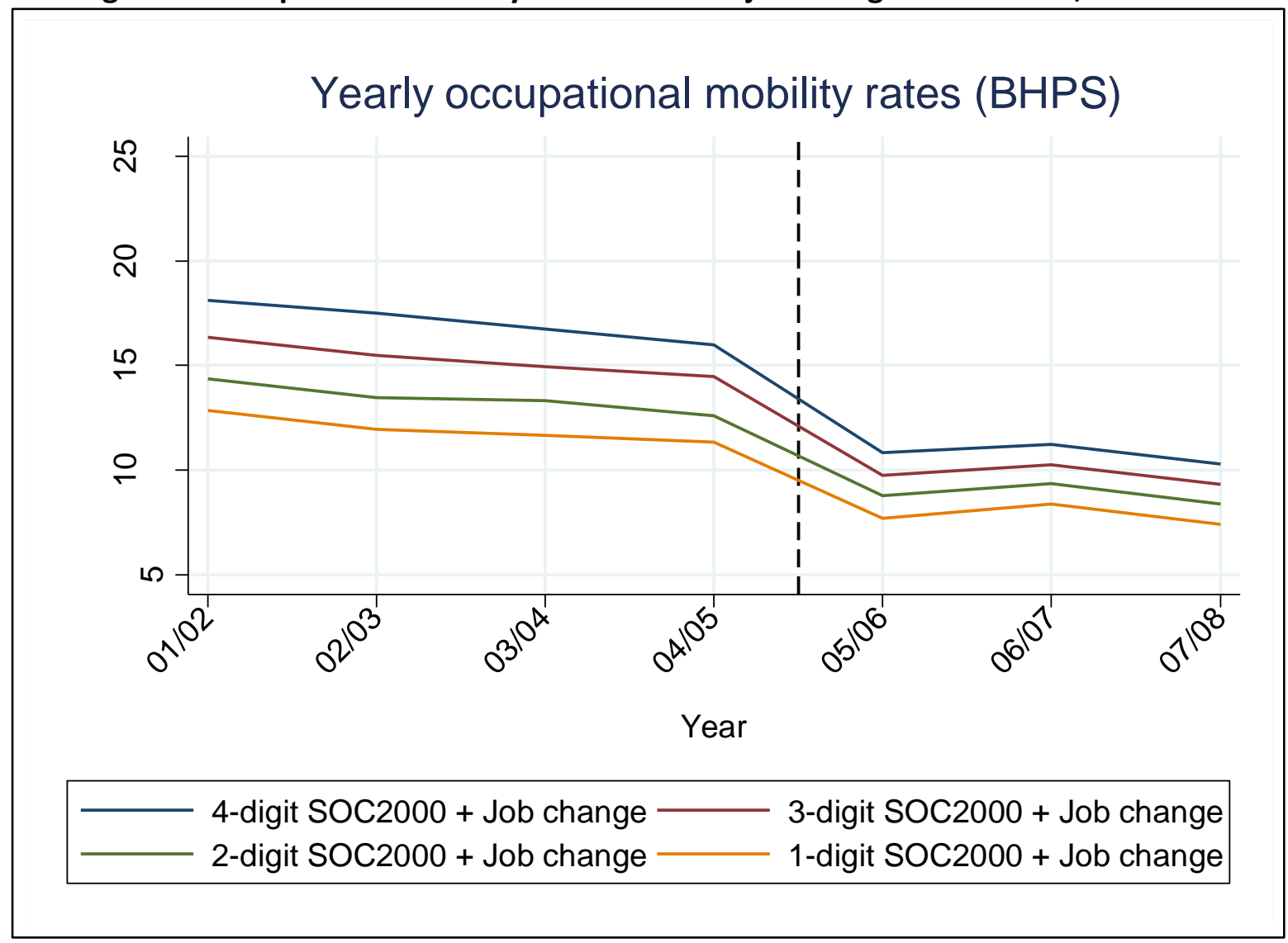


We now turn to discuss occupational mobility trends in Australia using the HILDA Survey data. Figure 5 shows trends for the period 2001-2012. As for the BHPS, we infer mobility using changes in occupational codes across adjacent survey instalments at each level of aggregation of the ANZSCO06 occupational classification. Additionally, we show trends based on the variable included in the survey that considers respondents' self-reports. Before we do this, it is worth noting how much the assessments of occupational mobility vary across measures. The measure of occupational change relying on respondents having different occupation codes and the measure based on respondents' selfreports disagree in $25-30 \%$ of cases and pairwise correlations between these are just 0.31-0.34.

The lines in the graph indicate that there is also a suspiciously high rate of occupational mobility in the Australian labour market - similar to that for Britain - which also increases with occupational disaggregation. Around $40 \%$ of workers appear to switch detailed occupational units each year, whereas around $25 \%$ seemingly move across major occupational groups. This is unsurprising, given that the HILDA Survey uses independent interviewing to collect occupational data throughout the life of the panel. A more interesting, novel piece of information emerges when examining the rates of occupational change calculated using respondents' self-reports. These are substantially lower than those calculated using occupational code mismatches across adjacent survey years and indicate that around $20 \%$ of all workers change occupations each year. The discrepancies with the 4-digit level of aggregation - arguably the level at which respondents judgments operate (Moscarini \& Thomsson, 2007) - are very high (20-25 percentage points). This strongly suggests that 'true' levels of occupational change are indeed lower than those typically inferred from occupational codes in panel studies. It is also worth noting that, unlike what was observed for the BHPS, there are no major shifts in the trend in the Australian panel data. To the extent that the labour markets in these two countries and the two panel surveys are comparable, this constitutes supporting evidence that it is the survey practice of dependent interviewing that is behind the shifts observed in Figures 1 to 4 for Britain.

Figure 5. Occupational mobility in the HILDA Survey, ANZSCO06

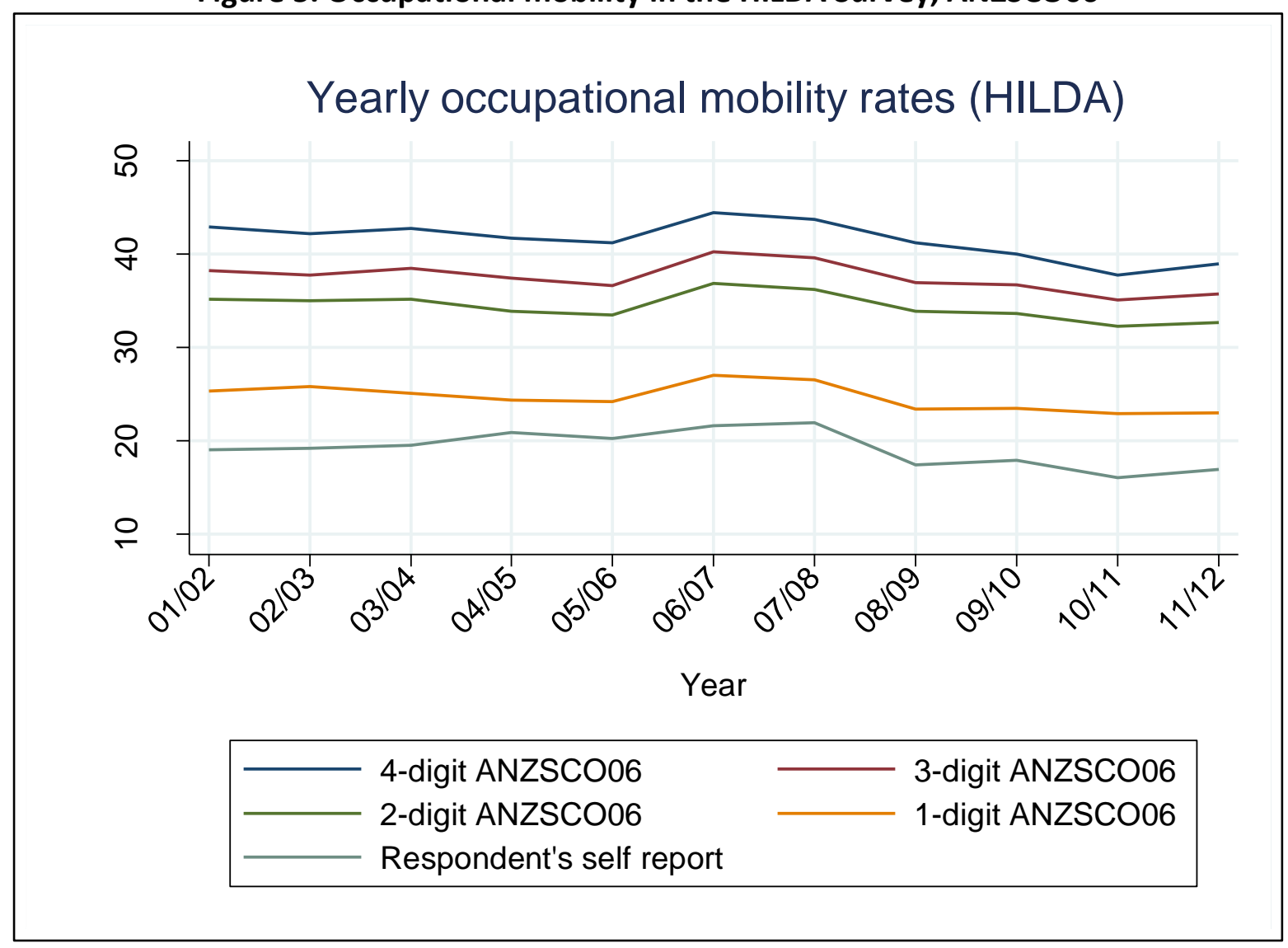




\section{The impact of occupational mobility on labour market outcomes}

Testing the external validity of survey measures requires assessing their relative performance in adhering to theoretical predictions. As discussed before, the sociological and economic literatures expect occupational mobility to be a vehicle for upward social mobility and, consequently, be accompanied by rises in wages and 'utility'. The latter notion is empirically approximated using information on job satisfaction (Frey \& Stutzer, 2002). In this part of the analysis, we test how the different measures of occupational change perform in predicting wages and job satisfaction in both Britain and Australia. Logically, the most valid measures will show the strongest partial correlations with these labour market outcomes.

We begin by looking at the BHPS using wage and job satisfaction change-score models of the following form:

$$
\begin{gathered}
\ln (\mathrm{W})_{\mathrm{it}}-\ln (\mathrm{W})_{\mathrm{it}-1}=\mathrm{a}+\mathrm{C}_{\mathrm{it}-1, \mathrm{t}} \beta+\mathrm{X}_{\mathrm{it}} \gamma+\mathrm{e}_{\mathrm{it}} \\
\mathrm{JS}_{\mathrm{it}}-\mathrm{JS}_{\mathrm{it}-1}=\mathrm{a}+\mathrm{C}_{\mathrm{it}-1, \mathrm{t}} \beta+\mathrm{X}_{\mathrm{it}} \gamma+\mathrm{e}_{\mathrm{it}}
\end{gathered}
$$

...where $\mathrm{i}$ and $\mathrm{t}$ subscripts stand for individual and time, $a$ is an intercept, $\ln (W)$ is the natural logarithm of hourly wages, JS denotes overall job satisfaction (on a scale from 1-7), $C$ is a given measure of occupational change, $\mathrm{X}$ is a vector of control variables, $e$ is the usual stochastic regression error term, and $\beta$ and $\nu$ are regression coefficients or vectors of coefficients to be estimated. Hourly wages are calculated using information on the number of usual weekly work hours and the usual gross monthly pay in the current main job, and adjusted for inflation using Consumer Price Indexes. The $X$ vector comprises control variables used in recent research on occupational mobility (Longhi \& Brynin, 2010): age group, gender, highest educational qualification, partnership status, number of children, part-time work, firm size, employment contract and private sector employment.

For simplicity, we estimate these equations using standard ordinary least squares regression. More complex models are possible using these data. For example, one could model job satisfaction as an ordered outcome, account for selection into employment and allow for unobserved heterogeneity. However, because the focus of this article is elsewhere and for simplicity's sake, we choose to estimate relatively simple and generalizable specifications. The models are fitted once for year 2004 (two years before the introduction of dependent interviewing) and once for year 2008 (after the introduction of dependent interviewing). We choose time periods that are two rather than one year away from the introduction of dependent interviewing because of the odd behaviour of occupational mobility rates in the year immediately following its implementation in 2006 observed in Figures 1 and 2. Results are presented in Table 1.

In the wage equation for 2004 (column 1) occupational mobility is captured by changes in occupational codes across adjacent survey years under independent interviewing conditions. Here, a change in occupation has no statistically significant impact on wage changes all else being equal, irrespective of the occupational classification (SOC90 or SOC2000) and level of occupational aggregation (1 to 4 digits) used. In the wage equation for year 2008 (column 2) occupational mobility is captured by changes in occupational codes across adjacent survey years under dependent interviewing. In these models, a change of occupation is associated with an increase of 2-3\% in hourly wages, which is in most cases statistically different from zero. Therefore, using changes in occupational codes across adjacent survey waves as evidence of occupational mobility yields results which are more consistent with theory under dependent than independent interviewing. This hints that the former is a more desirable way to collect occupational data in panel studies.

We now turn our attention to the job satisfaction equations in columns 3 and 4 . Occupational mobility is associated with increased job satisfaction under both interview practices, but more strongly so under dependent than independent interviewing. In the BHPS, job satisfaction is measured on a scale from 1 to 7 . The magnitude of the impacts is of 0.12-0.19 units in the equation for year 2004 under independent interviewing, and a much higher 0.49-0.58 units in the equation for year 2008 under dependent interviewing. Again, this is evidence in support of the idea that, if occupational change is inferred by changes in occupational codes, dependent interviewing is a more desirable survey feature than independent interviewing. ${ }^{\mathrm{vi}}$ 
Table 1. Impacts of occupational change on wages and job satisfaction in the BHPS

\begin{tabular}{lrccc} 
Occupational mobility & \multicolumn{4}{c}{ Y=Change in... } \\
\cline { 2 - 5 } measured as a... & \multicolumn{2}{c}{ Log hourly wages } & Job satisfaction \\
& $\mathbf{2 0 0 4}$ & $\mathbf{2 0 0 8}$ & $\mathbf{2 0 0 4}$ & $\mathbf{2 0 0 8}$ \\
\hline 4-digit SOC90 change & -0.004 & $0.033^{* *}$ & $0.190^{* * *}$ & $0.550^{* * *}$ \\
3-digit SOC90 change & -0.001 & $0.037^{* *}$ & $0.181^{* * *}$ & $0.551^{* * *}$ \\
2-digit SOC90 change & -0.003 & 0.021 & $0.156^{* * *}$ & $0.536^{* * *}$ \\
1-digit SOC90 change & -0.005 & $0.032^{*}$ & $0.125^{* *}$ & $0.491^{* * *}$ \\
\hline 4-digit SOC2000 change & -0.001 & $0.026^{*}$ & $0.177^{* * *}$ & $0.570^{* * *}$ \\
3-digit SOC2000 change & 0.001 & $0.025^{*}$ & $0.175^{* * *}$ & $0.567^{* * *}$ \\
2-digit SOC2000 change & 0.006 & $0.024\left(^{*}\right)$ & $0.188^{* * *}$ & $0.582^{* * *}$ \\
1-digit SOC2000 change & 0.008 & $0.023\left(^{*}\right)$ & $0.183^{* * *}$ & $0.544^{* * *}$ \\
\hline$n$ & 5,192 & 4,847 & 5,233 & 4,910 \\
\hline
\end{tabular}

Notes. OLS models. 1991-2008. Control variables include age group, gender, highest educational qualification, partnership status, number of children, part-time work, firm size, employment contract, and private sector employment. Significance levels: $(*) 0.1, * 0.05, * * 0.01, * * * 0.001$.

Similar regression models to those estimated above are fitted using all 12 available waves of the HILDA Survey data. This time, we compare the performance in predicting change in wages and job satisfaction of measures of occupational mobility based on individuals having different occupational codes across adjacent survey years and respondents' self-reports. Results are presented in Table 2 .

Column 1 contains the results of wage equations. When using occupational mobility measures in which change is inferred from occupational codes, the predicted impacts of occupational moves on wage changes are very small $(0.4 \%-0.6 \%)$ and sometimes not (or only marginally) statistically significant. In contrast, the measure of mobility constructed from self-reports performs much better: it predicts a growth of $1.8 \%$ in hourly wages following occupational switches and the associated coefficient is statistically significant at the $99.9 \%$ level.

Table 2. Impacts of occupational change on wages and job satisfaction in the HILDA Survey

\begin{tabular}{lcr} 
Occupational mobility & \multicolumn{2}{c}{ Y=Change in... } \\
\cline { 2 - 3 } measured as $\boldsymbol{a} . .$. & Log hourly wages & Job satisfaction \\
\hline 4-digit ANZSCO06 change & $0.006^{*}$ & $0.233^{* * *}$ \\
3-digit ANZSCO06 change & $0.006^{*}$ & $0.255^{* * *}$ \\
2-digit ANZSCO06 change & $0.006\left(^{*}\right)$ & $0.264^{* * *}$ \\
1-digit ANZSCO06 change & 0.004 & $0.282^{* * *}$ \\
\hline Self-reported occupation change & $0.018^{* * *}$ & $0.553^{* * *}$ \\
\hline$n$ (observations) & 60,874 & 63,907 \\
$n$ (individuals & 12,832 & 13,153 \\
\hline
\end{tabular}

Notes. OLS models with standard errors adjusted for the clustering of observations within individuals. 2001-2012. Control variables include age group, gender, highest educational qualification, partnership status, number of children, part-time work, firm size, employment contract, and private sector employment. Significance levels: $\left({ }^{*}\right) 0.1,{ }^{*} 0.05, * *$ $0.01, * * * 0.001$. 
Column 2 contains the results of equivalent job satisfaction models. Note that overall job satisfaction has a different range in the HILDA Survey of $0-10$, and so the magnitude of the reported effects is not comparable to that of the effects reported for the BHPS. As for the BHPS, all measures of occupational mobility are associated with growth in job satisfaction. However, all else being equal, self-reported occupational changes are more strongly associated with job satisfaction (they increase it by 0.55 units) than are occupational mobility measures based on changes in occupational codes (0.23-0.28 units).

These results provide clear evidence that, under independent interviewing, self-reported measures of occupational change deliver results which are more consistent with theoretical expectations than measures based on occupational codes. This suggests that the former might be a better construct to capture occupational mobility in panel surveys, and studies other than the HILDA Survey would benefit from its inclusion.

\section{Discussion and conclusion}

Longitudinal data on occupation of work is of key importance to research in the sociology of work and labour economics, but the quality of information on occupational mobility in panel surveys is suspected to be poor due to measurement error. In this paper we have examined the consistency of data on occupational change in panel studies via separate analyses of the BHPS and the HILDA Survey.

Consistent with our first and main research hypothesis, analysis of BHPS data evidences that the switch from independent to dependent interviewing in the collection of occupation data in this survey substantially reduced the implausibly high, previously observed mobility rates. This suggests that, when occupation-related data are collected via independent interviewing, measurement error is high. Also as expected, the fall in mobility rates was more visible for more disaggregated versions of occupational classifications than for more aggregated versions, implying that the error is more pervasive in detailed schemas. The latter is unfortunate, as highly disaggregated occupational units convey the most valuable information to social and behavioural scientists. Using supplementary information on job mobility to separate spurious from 'true' occupational switches is a useful though imperfect tool to correct for these issues under independent interviewing conditions.

Analysis of the HILDA Survey further indicated that respondents' self-reports of occupational switches often conflict with mobility inferred from changes in occupational codes across survey waves and depict more modest yearly rates of occupational mobility. This is consistent with our third hypothesis and constitutes supporting evidence for the argument that, under independent interviewing conditions, inferring occupational mobility from changes in occupational codes across survey waves is problematic and does not necessarily capture 'true' change. Adding to this view and in line with hypotheses 4 and 5 , the impacts of occupational changes on earnings and job satisfaction are more consistent with theoretical predictions after the introduction of dependent interviewing in the BHPS and when occupational mobility is inferred from respondents' self-reports in the HILDA Survey.

Substantively, our preferred estimates suggest that the 'true' extent of year-on-year occupational mobility is $10-15 \%$ in Britain and $15-20 \%$ in Australia, and that occupational switches have nonnegligible effects on the wages and overall job satisfaction of workers in both countries.

Based on these results, we conclude that measurement error in occupational mobility in panel surveys can be very high, to a level that is intolerable and has the potential to severely distort research findings. This has important implications. Our results are applicable to other panel datasets which employ the 'traditional' method of independent interviewing to collect occupationrelated data, including the HILDA Survey, the German Socio-Economic Panel (see Isaoglu, 2010) and other studies affiliated to the CNEF, and should be taken into account in the design and re-design of panel surveys that collect data on occupation of work. In particular, the implementation of dependent interviewing practices and the inclusion of survey questions capturing perceived occupational mobility are desirable courses of action. The patterns reported here also highlight the need to revise findings from existing research studies that take the quality of occupational mobility data in panel surveys for granted. Due to the statistical noise produced by this type of measurement error, 'true' relationships might have gone unnoticed, whereas correlation of the errors 
with individual- and occupation-level traits might have given rise to spurious associations (Sullivan, 2009). Additionally, any survey measures derived from occupational mobility/stability data, such as tenure in an occupation as a proxy for occupationspecific human capital, will be affected (Kambourov \& Manovskii, 2009; Sullivan, 2009).

There are, however, caveats to this research which must be kept in mind when interpreting its findings and which might hopefully inspire further inquiry. First, in our BHPS analyses we do not observe rates of occupational mobility under independent and dependent interviewing synchronically, that is, for the same survey year. This implies that, although this is highly unlikely, we cannot explicitly rule out that the reported breaks in the trends in occupational mobility after the adoption of dependent interviewing practices are partially the product of real changes in the prevalence of this phenomenon, or of some other mechanism such as non-random panel attrition.

Second, implementation of dependent interviewing in the BHPS might not only be associated with a decrease in misclassification in occupational reports, but also with an increase in other survey errors, such as acquiescence bias (Hill, 1994; Jäckle, 2009; Lugtig \& Lensvelt-Mulders, 2013; Mathiowetz \& McGonagle, 2000). Given the routing in the relevant BHPS module, if undecided or unknowledgeable respondents do have a tendency to agree with the statement presented to them, then dependent interviewing would produce downwards-biased estimates of change. For instance, respondents might report occupational stability even if some new element, such as managerial duties, has come into their jobs and effectively places then into a different occupation. Alternatively, agreeing might be an act of 'satisficing' to avoid having to provide a new occupational description (a relatively lengthy process). However, Jäckle et al. (2007) found no evidence of this sort of satisficing behaviour in evaluating the introduction of dependent interviewing in the BHPS, and acquiescence bias is usually most problematic in long batteries of similarly structured questions and in telephone interviews, neither of which is the case here.

Third, self-reported measures of occupational mobility are not perfect either: respondents might lack knowledge on what exactly constitutes a change in occupation, as opposed to both stability and other types of mobility (e.g. job changes and employer changes). Given how difficult it is to delimit detailed occupations, these measures may in fact understate 'true' mobility levels if respondents tend to report stability when unsure. Such measures may also be polluted by measurement error due to poor recalls of the timing of switches relative to the previous interview date, with the resulting errors likely to be more prevalent when the two events take place within a short time period. ${ }^{\text {vii }}$

It would be difficult to test the degree to which these mechanisms affect our findings using existing data. However, the robustness of our results could be thoroughly examined via survey experimentation. Devices such as the UK Household Longitudinal Study: Understanding Society Innovation Panel (Buck \& McFall, 2012) could be used for such an endeavour. In addition, the refinement of models that allow for misclassification in occupational reports is urgently needed to improve the analysis of existing longitudinal datasets in which occupation-related information has been collected in non-optimal ways (Sullivan, 2009). It is highly likely that the type of measurement error in panel datasets considered in this paper is confined to occupation-related information, and hence exploring its incidence in other work-related information, such as data on industry of work (Lynn \& Sala, 2006), would prove a fruitful avenue for further research. Additionally, future studies could advance the findings reported here by examining whether longitudinal inconsistencies in occupational reports are random or, instead, affect certain types of individuals and occupations more than others. 


\section{Acknowledgements}

The author would like to thank Nicole Watson, Noah Uhrig and Wojtek Tomaszewski for helpful comments and suggestions on an earlier version of this paper, Simonetta Longhi for sharing her expertise on job changing in BHPS data, and three anonymous LLCS referees for comments and suggestions that added substantive value to this work. The BHPS data used in this paper were made available through the ESRC Data Archive. The BHPS data were originally collected by the ESRC Research Centre on Micro-social Change at the University of Essex (now incorporated within the Institute for Social and Economic Research). Neither the original collectors of the data nor the Archive bear any responsibility for the analyses or interpretations presented here. This paper also uses unit record data from the HILDA Survey. The HILDA Project was initiated and is funded by the Australian Government Department of Social Services (DSS) and is managed by the Melbourne Institute of Applied Economic and Social Research (Melbourne Institute). The findings and views reported in this paper, however, are those of the author and should not be attributed to either DSS or the Melbourne Institute.

\section{References}

Abbott, A. (1989). The new occupational structure: What are the questions? Work and Occupations, 16 (3), 273-291. http://dx.doi.org/10.1177/0730888489016003002

Blau, P. M., \& Duncan, O. D. (1967). The American occupational structure. New York: Wiley.

Booth, A. L., \& Francesconi, M. (1999). Job mobility in 1990s Britain: Does gender matter? ISER Working Papers. Colchester: University of Essex.

Borjas, G. (1981). Job mobility and earnings over the life cycle. Industrial \& Labor Relations Review, 34 (3), 377-388. http://dx.doi.org/10.2307/2522783

Brown, J., \& Light, A. (1992). Interpreting panel data on job tenure. Journal of Labor Economics, 10 (3), 219257. http://dx.doi.org/10.1086/298286

Buck, N., \& McFall, S. (2012). Understanding Society: Design overview. Longitudinal and Life Course Studies, 3 (1), 5-17.

Bukodi, E., \& Dex, S. (2010). Bad start: Is there a way up? Gender differences in the effect of initial occupation on early career mobility in Britain. European Sociological Review, 26 (4), 431-446. http://dx.doi.org/10.1093/esr/jcp030

Campanelli, P., Thomson K., Moon, N., \& Staples, T. (1997). The quality of occupational coding in the UK. In L. Lyberg, P. Biemer, M. Collins, E. de Leeuw, C. Dippo, N. Schwarz, \& D. Trewin (Eds.) Survey measurement and process quality (pp. 437-457). New York: Wiley.

Chan, T. W., \& Goldthorpe, J. H. (2007). Social stratification and cultural consumption: Music in England. European Sociological Review, 23 (1), 1-29. http://dx.doi.org/10.1093/esr/jcl016

De Beyer, J., \& Knight, J. B. (1989). The role of occupation in the determination of wages. Oxford Economic Papers, 41 (3), 595-618.

Elias P. (1997). Occupation classification (ISCO-88): Concepts, methods, reliability, validity and cross-national comparability. OECD Labour Market and Social Policy Occasional Papers 20, OECD Publishing. http://dx.doi.org/10.1787/304441717388

European Foundation for the Improvement of Living and Working Conditions. (1997). Voluntary and forced job mobility in Europe. Accessed $21^{\text {st }}$ of February 2014 from: http://www.eurofound.europa.eu/pubdocs/2007/12/en/1/ef0712en.pdf.

Evans, P. (1999). Occupational downgrading and upgrading in Britain. Economica, 66 (261), 79-96. http://dx.doi.org/10.1111/1468-0335.00157

Featherman, D. L., Lancaster Jones, F., \& Hauser, R. M. (1975). Assumptions of mobility research in the United States: The case of occupational status. Social Science Research, 4 (4), 329-360. http://dx.doi.org/10.1016/0049-089X(75)90002-2

Frey, B. S., \& Stutzer, A. (2002). What can economists learn from happiness research? Journal of Economic Literature, 40 (2), 402-425. http://dx.doi.org/10.1257/jel.40.2.402

Groot, W., \& Verberne, M. (1997). Aging, job mobility, and compensation. Oxford Economic Papers, 49 (3), 380-403. http://dx.doi.org/10.1093/oxfordjournals.oep.a028615

Goldthorpe, J. H. (1987). Social mobility and class structure in modern Britain ( $2^{\text {nd }}$ edition). Oxford: Clarendon.

Groves, R. M. (1989). Survey errors and survey costs. Wiley, New York. http://dx.doi.org/10.1002/0471725277

Harper, B. (1995). Male occupational mobility in Britain. Oxford Bulletin of Economics and Statistics, 57 (3), 349-369. http://dx.doi.org/10.1111/i.1468-0084.1995.mp57003005.x

Hill, D. H. (1994). The relative empirical validity of independent and dependent data in a panel survey. Journal of Official Statistics, 10 (4), 359-380. 
Isaoglu, A. (2010). Occupational affiliation data and measurement errors in the German Socio-Economic Panel. SOEP Papers on Multidisciplinary Panel Data Research 318. Berlin: Deutsches Institut für Wirtschaftsforschung.

Jäckle, A., Laurie, H., \& Uhrig, S. C. N. (2007). The introduction of dependent interviewing on the British Household Panel Survey. ISER Working Papers, 2007-07. Colchester: University of Essex.

Jäckle, A. (2009). Dependent interviewing: A framework and application to current research. In P. Lynn (Ed.) Methodology of longitudinal surveys (pp. 93-112). Chichester: John Wiley. http://dx.doi.org/10.1002/9780470743874.ch6

Jacobs, S. (1999). Trends in women's career patterns and in gender occupational mobility in Britain. Gender, Work and Organization, 6 (1), 32-46. http://dx.doi.org/10.1111/1468-0432.00067

Kambourov, G., \& Manovskii, I. (2008). Rising occupational and industry mobility in the United States: 196897. International Economic Review, 49 (1), 41-79. http://dx.doi.org/10.1111/i.14682354.2008.00473.x

Kambourov, G., \& Manovskii, I. (2009). Occupational specificity of human capital. International Economic Review, 50 (1), 63-115. http://dx.doi.org/10.1111/j.1468-2354.2008.00524.x

Kish, L. (1965). Survey sampling. New York: John Wiley \& Sons.

Laurie, H., \& Moon, N. (2003). The reliability of coding occupational descriptions: Measurement issues in a CAPI panel survey. ISER Working Papers, 2003-13. Colchester: University of Essex.

Lee, K., Carswell, J., \& Allen, N. (2000). A meta-analytic review of occupational commitment: Relations with person and work-related variables. Journal of Applied Psychology, 85 (5), 799-811. http://dx.doi.org/10.1037/0021-9010.85.5.799

Longhi, S., \& Brynin, M. (2010). Occupational change in Britain and Germany. Labour Economics, 17 (4), $655-$ 666. http://dx.doi.org/10.1016/i.labeco.2010.02.001

Lugtig, P., \& Lensvelt-Mulders, G. J. L. M. (2013). Evaluating the effect of dependent interviewing on the quality of measures of change. Field Methods (forthcoming).

Lynn, P., \& Sala, E. (2006). Measuring change in employment characteristics: The effects of dependent interviewing. International Journal of Public Opinion Research, 18 (4), 500-509. http://dx.doi.org/10.1093/ijpor/edl013

Mathiowetz, N. A., \& McGonagle, K. A. (2000). An assessment of the current state of dependent interviewing in household surveys. Journal of Official Statistics, 16 (4), 401-418.

Mellow, W., \& Sider, H. (1983). Accuracy of response in labor market surveys: Evidence and implications. Journal of Labor Economics, 1 (4), 331-344. http://dx.doi.org/10.1086/298016

Moscarini, G., \& Thomsson, K. (2007). Occupational and job mobility in the US. Scandinavian Journal of Economics, 109 (4), 807-836. http://dx.doi.org/10.1111/j.1467-9442.2007.00510.x

Parrado, E., Caner, A., \& Wolff, E. N. (2007). Occupational and industrial mobility in the United States. Labour Economics, 14 (3), 435-455. http://dx.doi.org/10.1016/j.labeco.2006.01.005

Perales, F. (2013). Occupational feminization, specialized human capital and wages: Evidence from the British labour market. Work, Employment and Society, 27 (4), 600-620. http://dx.doi.org/10.1177/0950017012460305

Polachek, S. W. (1981). Occupational self-selection: A human capital approach to sex differences in occupational structure. Reviews of Economics and Statistics, 63 (1), 60-69. http://dx.doi.org/10.2307/1924218

Sobek, M. (1996). Work, status, and income: Men in the American occupational structure since the late nineteenth century. Social Science History, 20 (2), 169-207. http://dx.doi.org/10.2307/1171236

Sorensen, A. B. (1974). A model for occupational careers. American Journal of Sociology, 80 (1), 44-57. http://dx.doi.org/10.1086/225761

Sullivan, P. (2009). Estimation of an occupational choice model when occupations are misclassified. Journal of Human Resources, 44 (2), 495-535. http://dx.doi.org/10.1353/ihr.2009.0030

Taylor, M. F., Brice, J., Buck, N., \& Prentice-Lane, E. (2010). British Household Panel Survey user manual volume A: Introduction, technical report and appendices. Colchester: University of Essex.

Watson, N., \& Summerfield, M. (2009). Quality of the occupation and industry coding in the HILDA Survey. HILDA Discussion Paper Series 3/09. Melbourne: Institute of Applied Economic and Social Research, University of Melbourne.

Watson, N., \& Wooden, M. (2012). The HILDA Survey: A case study in the design and development of a successful household panel study. Longitudinal and Life Course Studies, 3 (3), 369-381.

Wilson, R. M., \& Green, C. (1990). Occupation, occupational change and movement within the income distribution. Eastern Economic Journal, 16 (3), 209-220. 


\section{Endnotes}

' From a total survey error perspective, four sources of error affect survey data: sampling, coverage, nonresponse, and measurement error (Kish, 1965; Groves, 1989). Here, we are concerned about the last of these components: measurement error.

ii Inter-coder reliability rates vary substantially with the complexity of the occupational classification used, especially with the number of occupational units (Campanelli, Thomson, Moon \& Staples, 1997). As a result, there is not a widely accepted threshold of what constitutes an acceptable inter-coder reliability rate.

Nevertheless, agreement rates over $75-80 \%$ are generally considered acceptable (Elias, 1997).

iii A large share of the sociological literature is devoted to examining inter-generational occupational mobility (i.e. the transmission of occupational attainment from parents to their offspring). Here, the focus is however on intra-generational (i.e. within-generation) occupational mobility.

iv The picture becomes substantially more complex when the reasons for the move are considered, most importantly whether separations are voluntary (i.e. worker-initiated) or forced (i.e. employer-initiated). While the former sort of moves should be associated with substantial wage gains, the latter need not. We cannot and do not incorporate this distinction into our analyses. However, existing research suggests that voluntary moves are three to four times more prevalent than forced moves (European Foundation for the Improvement of Living and Working Conditions, 1997; Harper, 1995). We would therefore expect the net effect of mobility on wages to be positive.

${ }^{\vee}$ After 2008, BHPS respondents were incorporated into a new panel survey (the UK Household Longitudinal Study: Understanding Society). However, use of the BHPS subsample of Understanding Society for our purposes is problematic. First and foremost, there was a two-year gap between 2008 and 2010 when BHPS respondents were not interviewed. This would make it difficult to infer year-on-year occupational changes. Second, Understanding Society data are only available for up to Wave 3, and thus its usage would add little to our analyses. Third, the global financial crisis reached the British labour market in 2008 and may have exerted a profound exogenous impact in long-term mobility trends.

vi We also estimated models using the occupational mobility measures that incorporate information on job changes. Results, not shown but available upon request, suggest that under independent interviewing these perform better than mobility measures based solely on changes in occupational codes in predicting change in job satisfaction, but not wage changes.

vii Additionally, it is possible that reverse causality is at play when respondents answer the question on selfreported occupational mobility in the HILDA Survey: individuals might be more inclined to remember a change or even catalogue a change as such if this was accompanied by a boost in either wages or job satisfaction. 
